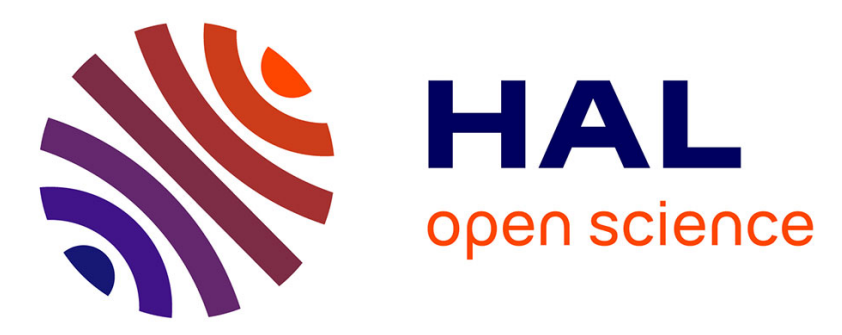

\title{
Influence of localized plasticity on oxidation behaviour of austenitic stainless steels under primary water reactor
}

Sarata Cissé, Lydia Laffont-Dantras, Marie-Christine Lafont, Benoit Tanguy, Eric Andrieu

\section{- To cite this version:}

Sarata Cissé, Lydia Laffont-Dantras, Marie-Christine Lafont, Benoit Tanguy, Eric Andrieu. Influence of localized plasticity on oxidation behaviour of austenitic stainless steels under primary water reactor. Journal of Nuclear Materials, 2013, vol. 433 (n 1-3), pp. 319-328. 10.1016/j.jnucmat.2012.09.020 . hal-01218526

\author{
HAL Id: hal-01218526 \\ https://hal.science/hal-01218526
}

Submitted on 21 Oct 2015

HAL is a multi-disciplinary open access archive for the deposit and dissemination of scientific research documents, whether they are published or not. The documents may come from teaching and research institutions in France or abroad, or from public or private research centers.
L'archive ouverte pluridisciplinaire HAL, est destinée au dépôt et à la diffusion de documents scientifiques de niveau recherche, publiés ou non, émanant des établissements d'enseignement et de recherche français ou étrangers, des laboratoires publics ou privés. 


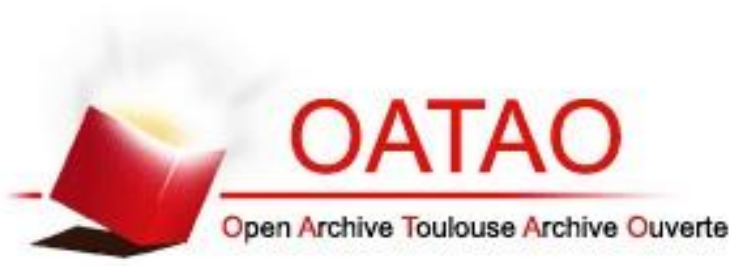

\section{Open Archive Toulouse Archive Ouverte (OATAO)}

OATAO is an open access repository that collects the work of Toulouse researchers and makes it freely available over the web where possible.

This is an author-deposited version published in: http://oatao.univ-toulouse.fr/ Eprints ID: 8790

To link to this article : DOI:10.1016/j.jnucmat.2012.09.020

URL : http://dx.doi.org/10.1016/j.jnucmat.2012.09.020

\section{To cite this version:}

Cissé, Sarata and Laffont, Lydia and Lafont, Marie-Christine and Tanguy, Benoit and Andrieu, Eric Influence of localized plasticity on oxidation behaviour of austenitic stainless steels under primary water reactor. (2013) Journal of Nuclear Materials, vol. 433 ( $\left.{ }^{\circ} 1-3\right)$. pp. 319-328. ISSN 0022-3115

Any correspondence concerning this service should be sent to the repository administrator: staff-oatao@ listes.diff.inp-toulouse.fr 


\title{
Influence of localized plasticity on oxidation behaviour of austenitic stainless steels under primary water reactor
}

\author{
Sarata Cissé ${ }^{\mathrm{a}}$, Lydia Laffont ${ }^{\mathrm{b}, *}$, Marie-Christine Lafont $^{\mathrm{b}}$, Benoit Tanguy ${ }^{\mathrm{a}}$, Eric Andrieu ${ }^{\mathrm{b}}$ \\ ${ }^{a}$ CEA Saclay, DEN/DANS/DMN/SEMI, 91191 Gif-sur-Yvette Cedex, France \\ ${ }^{\mathrm{b}}$ Institut CARNOT, CIRIMAT-ENSIACET, 4 allée Emile Monso, 31030 Toulouse Cedex 4, France
}

\begin{abstract}
A B S T R A C T
The sensitivity of precipitation-strengthened A286 austenitic stainless steel to stress corrosion cracking was studied by means of slow-strain-rate tests. First, alloy cold working by low cycle fatigue (LCF) was investigated. Fatigue tests under plastic strain control were performed at different strain levels $\left(\Delta \varepsilon_{p} / 2=0.2 \%, 0.5 \%, 0.8 \%\right.$ and $\left.2 \%\right)$ to establish correlations between stress softening and the deformation microstructure resulting from the LCF tests. Deformed microstructures were identified through TEM investigations. The interaction between oxidation and localized deformation bands was also studied and it resulted that localized deformation bands are not preferential oxide growth channels. The pre-cycling of the alloy did not modify its oxidation behaviour. However, intergranular oxidation in the subsurface under the oxide layer formed after exposure to PWR primary water was shown.
\end{abstract}

\section{Introduction}

IASCC (irradiation-assisted stress corrosion cracking) is a complex phenomenon affecting core reactor components, discovered in the 1990s. It consists in degradation resulting from microscopic brittle cracks, when ductile material undergoes mechanical loading in an aggressive environment. The complexity of IASCC is actually due to the simultaneous actions of material parameters, chemical environment, loads and irradiation effects. Currently, the mechanisms underlying this phenomenon are only partially understood. Numerous reviews [1-6] have pointed out that modifications in the material and the environment due to neutron irradiation contribute to IASCC: radiation hardening, radiation-induced segregation, water radiolysis (mainly in Boiling Water Reactor environments) and chemical species transmutations. Although all these factors are important for IASCC degradation, none appear to be the primary cause and the issue is still open. Recent works [7-11] identify plastic strain localization as another important contributing factor of IASCC. Onchi et al. [8] suggested that crack initiation in sensitized 304 SS may be linked to the presence of deformation bands. Jiao et al. [9] correlated different stacking fault energy (SFE) values (related to the propensity towards strain localization, in stainless steel irradiated to up to $5 \mathrm{dpa}$ ) to their intergranular percentage on the fracture surface in constant extension rate tensile (CERT) tests conducted under an argon atmosphere at $288^{\circ} \mathrm{C}$. It was shown that the intergranular (IG) percentage on fracture surfaces was higher for lower SFE materials i.e. where

\footnotetext{
* Corresponding author. Tel.: +33 5343234 37; fax: +33 534323498 . E-mail address: lydia.laffont@ensiacet.fr (L. Laffont).
}

the deformation is more localized. However, it should be noted that the steel doping that leads to SFE modification also impacts radiation-induced segregation, which is a potential factor impacting IASCC. Dislocation channelling is the deformation mode responsible for plastic deformation localization in pure metals such as $\mathrm{Cu}$ or $\mathrm{Al}$ [12]. For austenitic stainless steels, localization may be characterized by channelling (high doses, high temperature and low stain rate) and twinning (low doses, low temperature and high stain rate). Onchi et al. [7,8] also suggested that the intersection between dislocation channels and grain boundaries constitutes a high concentration stress and strain area, leading to a preferential crack initiation area. Given this, it could be useful to understand how oxide species grow on the surface of specimens with localized deformation bands, in other words if in static conditions, localized deformation bands may be considered as preferential sites for oxide growth. The study of Fournier et al. [11] on a A286 steel was along these lines. Deformation microstructure was simulated by means of low cycle fatigue (LCF), knowing that cyclic softening results in defect-free localized deformation bands. LCF tests were conducted at room temperature under $0.2 \%$ half-amplitude plastic strain. It was shown that A286 pre-strained by LCF is more sensitive to stress corrosion cracking (SCC) than the same alloy without localized deformation bands.

In order to study the impact of the degree of localization on SCC sensitivity, the same idea as that developed in [11] is explored in this paper. LCF tests at plastic strain amplitude $\left(\Delta \varepsilon_{p} / 2=0.2,0.5\right.$, $0.8 \%$ and $2 \%$ ) were performed and the resulting deformation microstructures were analyzed by transmission electron microscopy (TEM) observations. Then interactions between the oxide layer and the plasticity features were studied on specimens, with or 
without localized deformation bands, exposed to simulated primary water reactor (PWR). Information was obtained concerning the way localized deformation bands modify oxide growth behaviour.

\section{Experimental details}

The material studied was a precipitation-strengthened A286 austenitic stainless steel provided by UGITECH (France) as $30 \mathrm{~mm}$ diameter rod. Chemical analyses were carried out by means of GDMS (glow discharge mass spectroscopy) analysis. The chemical composition of the alloy is shown in Table 1 . The alloy underwent the following heat treatment: (i) solution annealing at $930{ }^{\circ} \mathrm{C}$ for $30 \mathrm{~min}$ in order to remove the mechanical history of the material, and (ii) water quenching to avoid internal oxidation. Specimens were encapsulated under primary vacuum in quartz tubes prior to heat treatment. An optimal ageing heat treatment leading to $\gamma^{\prime}$ precipitate nucleation was reported by Fournier et al. [11]. This heat treatment (ageing $50 \mathrm{~h}$ at $670^{\circ} \mathrm{C}$ ) implemented for A286 leading to $\gamma^{\prime}$ precipitate formation and avoiding the formation of $\eta$ phase on grain boundaries, known to be deleterious for the mechanical properties of the alloy.

In order to determine the average grain size, electro back scattering diffraction (EBSD) was performed on aged material. EBSD maps were obtained using a JEOL JSM 6400 SEM working at $30 \mathrm{kV}$. For these analyses, the samples were ground by SiC abrasive papers of grades from 120 to 2400 and were electropolished in a solution of $70 \%$ ethanol, $20 \%$ glycerol and $10 \%$ perchloric acid for $28 \mathrm{~s}$ under $27 \mathrm{~V}$ and $9 \mathrm{~A}$ (potentiostat values). The aim of this final polishing was to remove cold working resulting from mechanical polishing. The average statistical grain size was obtained over 850 grains; it was $15 \mu \mathrm{m}$ with a standard deviation of $9 \mu \mathrm{m}$.

\subsection{Low cycle fatigue tests}

Smooth cylindrical specimens, machined from heat-aged rods were used for the LCF tests. A final geometry of $4 \mathrm{~mm}$ diameter and $16 \mathrm{~mm}$ length (Fig. 1) was chosen after studying the buckling behaviour of the alloy under cyclic loading.

Plastic strain amplitude fatigue tests were performed at room temperature in ambient air using an Instron servohydraulic machine. The tests were carried out with plastic strain half-amplitude limits between 0.2 and $2.0 \%$. A triangular waveform signal with zero mean strain was used and the test frequencies for each strain amplitude are presented in Table 2. For each plastic strain amplitude, the tests were doubled and stopped at the same stress state. Thus, two microstructural conditions have the same macrostructural stress amplitude: a short test stopped before the hardening peak and a long test stopped in the early stages of the cyclic softening phase.

TEM characterization of the deformation microstructure was performed using a Jeol JEM 2010 operating at $200 \mathrm{kV}$ at the TEMSCAN service of Paul Sabatier University (Toulouse, France). TEM foils were obtained from thin slices ( $1 \mathrm{~mm}$ thickness) of the fatigue specimens. The thin slices were mechanically ground to $80-$ $100 \mu \mathrm{m}$, and then electropolished in a solution containing $8 \mathrm{vol} . \%$ perchloric acid, 17 vol.\% butoxy-2 ethanol and 75 vol.\% methanol, using a Tenupol twin jet at a potential of $22 \mathrm{~V}$ and a temperature of $263 \mathrm{~K}$.

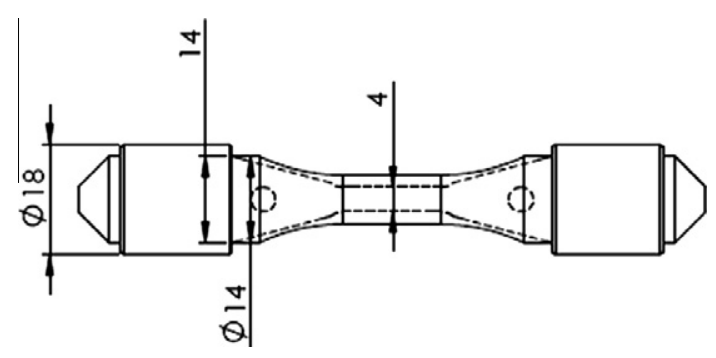

Fig. 1. Schematic representation of cylindric traction samples machined from a LCF specimen.

Table 2

Cycling frequency.

\begin{tabular}{ll}
\hline Plastic strain amplitude (\%) & Frequency $(\mathrm{Hz})$ \\
\hline 0.2 & 0.05 \\
0.5 & 0.02 \\
0.8 & 0.0125 \\
2 & 0.0005 \\
\hline
\end{tabular}

\subsection{Static oxidation and surface characterization}

Two kinds of specimen were tested in the oxidation section: (1) specimen without deformation - rectangular samples $\left(10 \times 10 \times 2 \mathrm{~mm}^{3}\right)$ machined from heat aged rods which are deformation free, (2) specimen deformed - small plates machined from pre-cycled fatigue specimens as displayed in Fig. 2.

These two specimens were ground on both sides by $\mathrm{SiC}$ papers of grades from 600 to 4000 , and polished using diamond pastes (from 3 to $1 \mu \mathrm{m}$ ) until a mirror surface was obtained. Finally the samples were carefully cleaned in ethanol and exposed to simulated reactor primary water at $340{ }^{\circ} \mathrm{C}$ for $500 \mathrm{~h}$ in a $231316 \mathrm{~L}$ stainless steel autoclave. The nominal composition of the simulated environment was $1000 \mathrm{mg} / \mathrm{l} \mathrm{H}_{3} \mathrm{BO}_{3}, 2 \mathrm{mg} / \mathrm{L} \mathrm{LiOH}$. An average content of $30 \mathrm{cc}$ dissolved hydrogen per $\mathrm{kg} \mathrm{H}_{2} \mathrm{O}$ was found during the test using an $\mathrm{Ag} / \mathrm{Pd}$ probe.

The post-exposed samples were carefully cleaned in ethanol, avoiding the removal of the oxide layer from the sample surface. For TEM analyses, cross-sections of the oxide layer were prepared by cutting the samples into thin slices (normal to the oxide/substrate interface) with a diamond wire saw. Two slices were glued together, oxide to oxide, and embedded in a 3-mm diameter brass tube in epoxy resin. After curing, the tube was sectioned into approximately $300-\mu \mathrm{m}$ thick discs which were then polished on both faces and dimpled before ion-milling to transparency with a low angle $\left(0-10^{\circ}\right)$ precision ion-beam polishing system (PIPS). Cross sections were then investigated, using a JEOL JEM 2010 microscope operated at $200 \mathrm{kV}$ and equipped with an energy dispersive spectrometer (EDS) for chemical analysis at University Paul Sabatier tEMsCAN Service (Toulouse, France).

In order to complete investigations into the nature of the oxide at the interface, under the oxide layer, SIMS analyses were carried out. Diffusion profiles of chemical elements or oxides were established from base metal to oxide layer and chemical element mapping of interesting elements performed by Reverse -SIMS analyses. R-SIMS consists of eroding the sample from base metal to oxide

Table 1

Chemical composition of the precipitation-strengthened A286 (wt.\%).

\begin{tabular}{|c|c|c|c|c|c|c|c|c|c|c|c|c|c|c|c|c|c|}
\hline Alloy & $\mathrm{Pb}$ & W & $\mathrm{Zr}$ & $S$ & $\mathrm{P}$ & C & $\mathrm{Mg}$ & Co & $\mathrm{Si}$ & $\mathrm{Cu}$ & V & Mo & $\mathrm{Mn}$ & $\mathrm{Ti}$ & $\mathrm{Ni}$ & $\mathrm{Cr}$ & $\mathrm{Fe}$ \\
\hline A286_Q12 & 3 ppm & 0.02 & $<1 \mathrm{ppm}$ & 0.002 & $<0.01$ & 0.025 & 08 & 0.09 & 0.48 & 0.1 & 0.23 & 1.01 & 1.5 & 2.02 & 25.2 & 14.2 & Bal \\
\hline
\end{tabular}




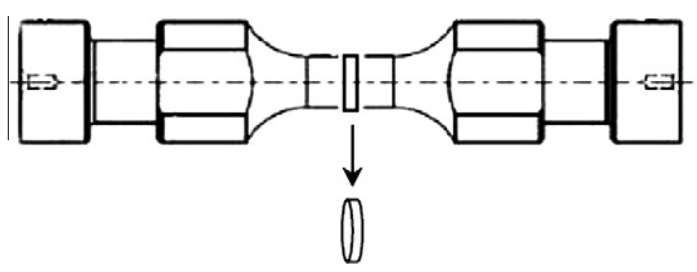

Fig. 2. Schematic representation of specimens containing localized deformation bands which are then exposed to simulated PWR water.

with a primary ion beam of energy $10 \mathrm{keV} \mathrm{Cs}{ }^{+}$to produce ionized secondary particles, subsequently detected by a mass spectrometer. R-SIMS permits to better detect the oxygen signal present in the sub-surface. The equipment, a CAMECA IMS 4F6 is located at the physics department of INSA Toulouse (France). Specimens to be analyzed were glued to a brass sampler so that the oxide was against the sampler. The sample was then ground by $\mathrm{SiC}$ papers (600-4000 grades) until sample thickness was less than $10 \mu \mathrm{m}$ and the surface at the base metal side was polished to a mirror finish using diamond pastes. The thin section was then released from the sampler and was ready for analysis.

\section{Results and discussion}

\subsection{Initial microstructure}

Ageing heat treatment of $50 \mathrm{~h}$ at $670{ }^{\circ} \mathrm{C}$ on $\mathrm{A} 286$ led to the formation of hardening phase: $\gamma^{\prime}\left(\mathrm{Ni}_{3} \mathrm{Ti}\right)$ precipitates in austenitic matrix. The interesting strengthening properties of the A286 alloy are due to this phase acting by microscopic mechanisms such as the Orowan mechanism [13] which is related to interactions between mobile dislocations and precipitates. As the contrast between $\gamma^{\prime}$ precipitates and $\gamma$ matrix is weak, precipitates are not easily revealed by bright field imaging. Dark-field TEM micrography is more suitable. A dark-field TEM image using the superlattice reflexion $(010)_{\gamma^{\prime}}$ of the [103] zone axis to image $\gamma^{\prime}$ precipitates is displayed in Fig. 3. The $\gamma^{\prime}$ phase crystallizes in a cubic structure (space group Pm-3m) with a lattice parameter $a=3.57 \AA$. This phase is coherent with an austenitic phase $\gamma$ matrix ( $\mathrm{Fm} 3 \mathrm{~m} a=3.60 \AA ̊)$.

According to small angle neutron scattering measurements performed at Leon Brillouin laboratory (CEA, France), the $\gamma^{\prime}$ precipitates had a mean diameter of $3.4 \mathrm{~nm}$, a distance between the precipitates of $15.3 \mathrm{~nm}$ and a volume fraction of $9.3 \%$.
Elements such as chromium and titanium which supersaturate the solid solution were out of equilibrium in the matrix reducing the solubility of carbon. The aim of solution annealing performed before ageing was to favor austenitic $\gamma$ matrix and to avoid precipitation, which occurs after combination between chromium or titanium and carbon at room temperature. However, despite annealing, residual precipitation remained. Three precipitate families were identified: titanium carbides, molybdenum carbides and titanium phosphides. Bright field images of these precipitates and their associated diffraction patterns are displayed in Fig. 4.

Titanium carbides (maximum size: $3 \mu \mathrm{m}$ ) grew in a facecentred cubic structure, space group Fm $3 \mathrm{~m}$ and lattice parameter $a=4.32 \AA$ (TiC) or $a=4.24 \AA$ (TiN). This phase, which is ovoidshaped, is often observed at grain boundaries and within grains.

Molybdenum carbides (maximum size: $800 \mathrm{~nm}$ ) are indexed using the $\mathrm{C}_{5} \mathrm{Fe}_{11} \mathrm{Mo}_{6}$ lattice (Handbook Pearson) which has a monoclinic structure (space group $\mathrm{C} 2 / \mathrm{m}$ ) with lattice parameters $a=10.86 \AA, b=7.76 \AA, c=6.56 \AA$ and $\alpha=90^{\circ}, \beta=120^{\circ}, \gamma=90^{\circ}$.

Titanium phosphides (maximum size: $400 \mathrm{~nm}$ ) are generally localized at grain boundaries. Their diffraction patterns were not obtainable due to their small size. Precipitates are often located within the matrix but also at grain boundaries and may lower the mechanical performance of the alloy.

\subsection{Stress response during low-cycle fatigue}

Fig. 5 plots the half-stress amplitude $(\Delta \sigma / 2)$ against the number of fatigue cycles for three plastic strain amplitudes in precipitation-hardened A286.

Global LCF behaviour is similar for the different levels of plastic strain. Three steps are distinguished: first the alloy work-hardens during the first cycles ( 9 cycles for $0.8 \%$ of plastic strain, 14 cycles for $0.5 \%$ and 18 cycles for $0.2 \%$ ) before showing cyclic softening. The last stage is the saturation of the softening. Macroscopic cyclic softening, in terms of stress, may be defined as the difference between the hardening peak stress and the stress level corresponding to the softening plateau. For the $0.8 \%$ plastic-strain half-amplitude test, the stress-strain curves for the 8th cycle (hardening peak cycle) and the 150th cycle (stabilized softening cycle) are shown in Fig. $6 a$ and exhibit a cyclic softening of $188 \mathrm{MPa}$. The cyclic softening (CS) was greater when plastic strain amplitude was increased, than when the hardening peak stress was increased.
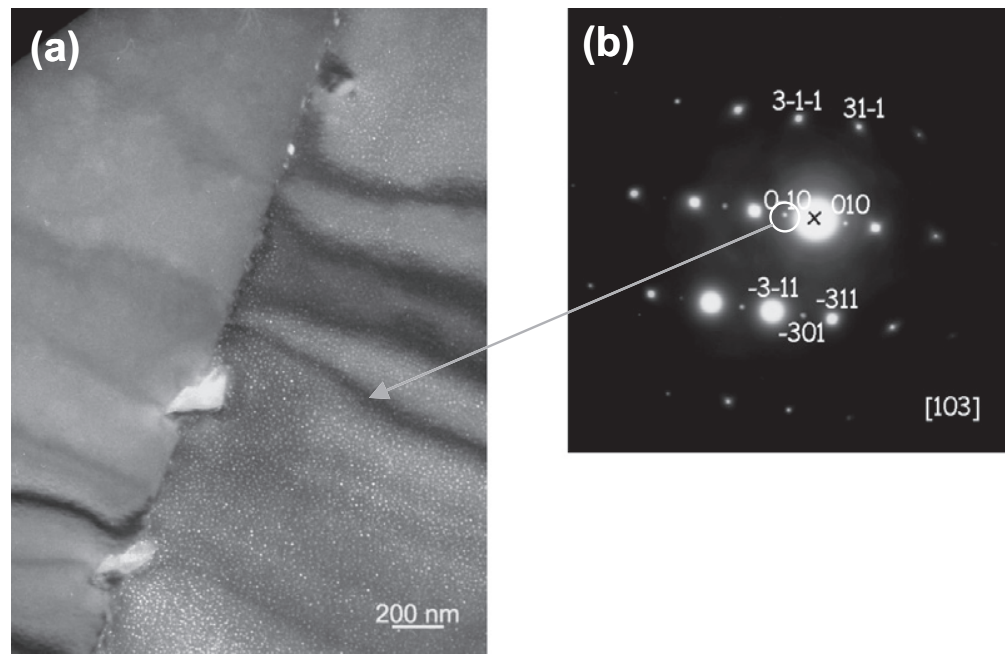

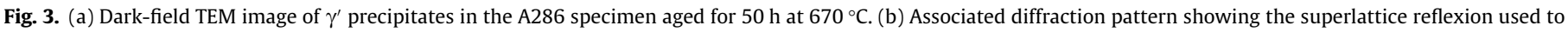
image the $\gamma^{\prime}$ precipitates (arrow) in zone axis [103] 

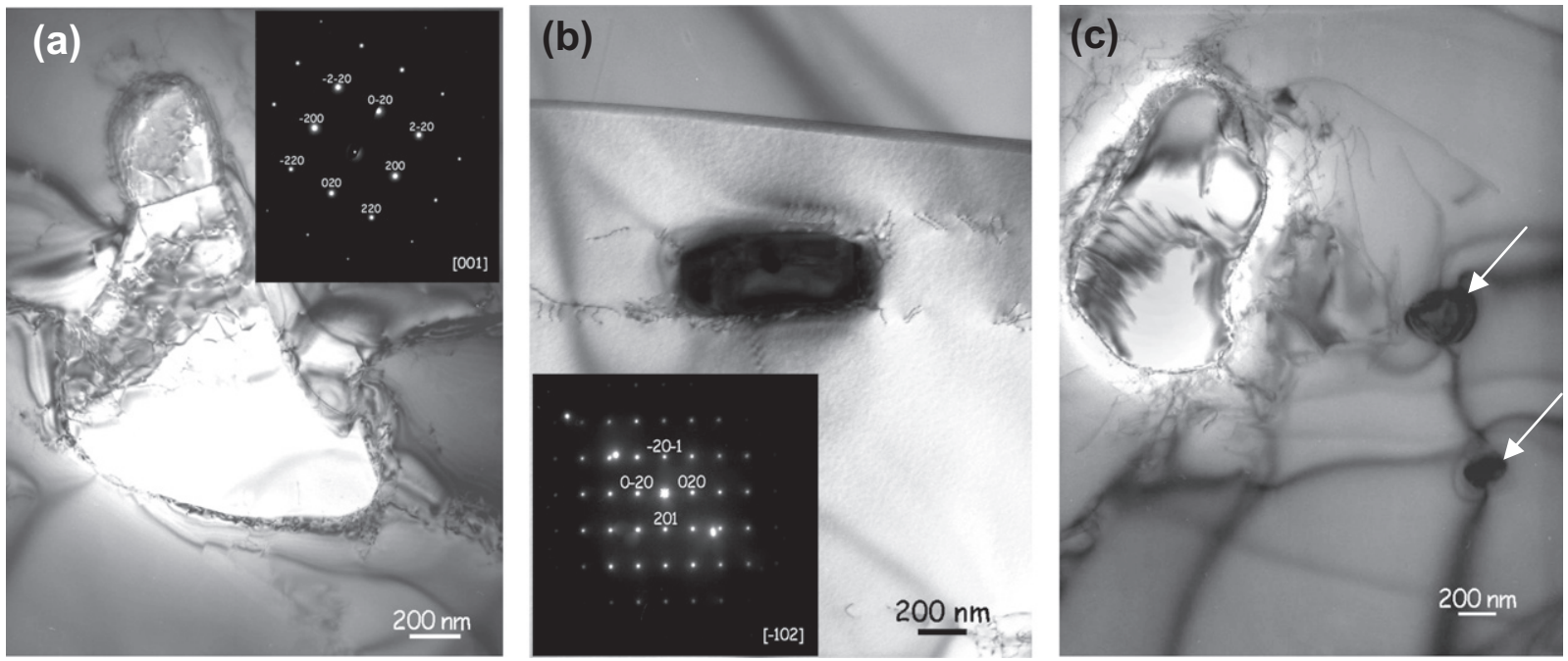

Fig. 4. (a) Bright field images of (a) $\mathrm{Ti}(\mathrm{C}, \mathrm{N})$ precipitate with the associated diffraction pattern in zone axis [001], (b) $\mathrm{C}_{5}\left(\mathrm{Fe}, \mathrm{Ti}, \mathrm{Cr}_{11} \mathrm{Mo}_{6} \mathrm{precipitate}\right.$ with the associated diffraction patterns in zone axis [-102] and (c) titanium phosphide precipitates (shown by white arrows).

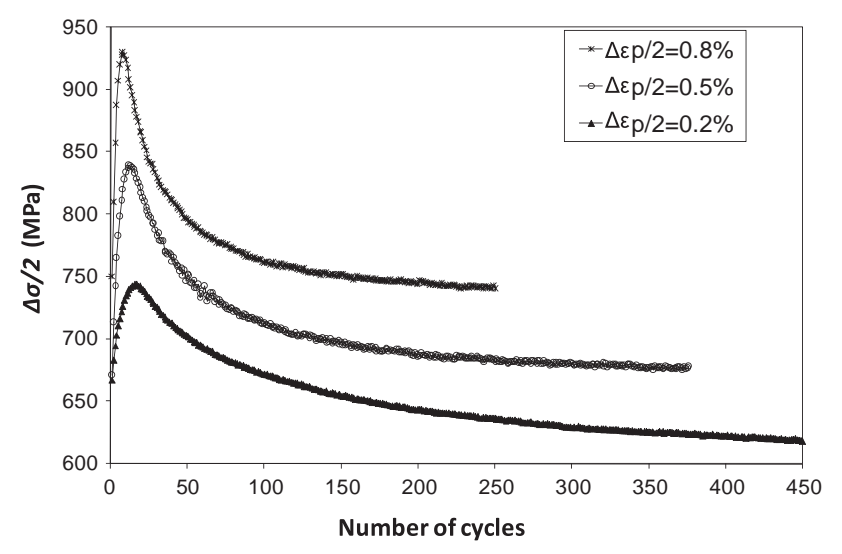

Fig. 5. Half true-strain amplitude $(\Delta \sigma / 2)$ versus number of cycles for the precipitation-hardened A286.

A typical plot of the experimental cyclic softening obtained after the LCF test versus plastic strain is presented in Fig. $6 \mathrm{~b}$.

The CS resulting from a 1000-cycle fatigue test for a solutionannealed A286 stainless steel aged at $670{ }^{\circ} \mathrm{C}$ for $50 \mathrm{~h}$ from [14] is

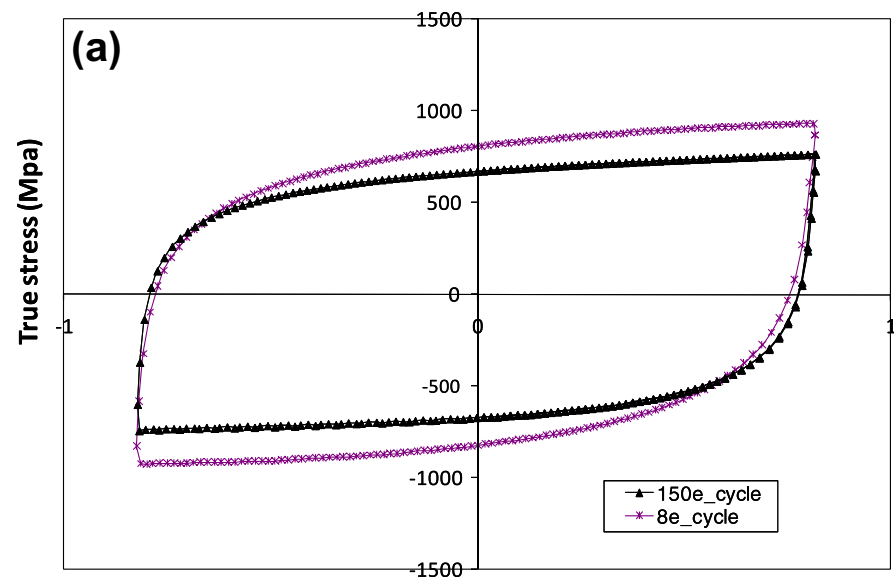

Plastic strain (\%) also reported in Fig. 6b. Note that under cyclic strain, cyclic softening exhibits an initial increase followed by saturation at higher plastic strain control values. This indicates that over one plastic strain value, softening does not vary any more (or little) and that there is a plastic strain range corresponding to the location of the plastic deformation in the alloy.

However, it can be noted that for $\Delta \varepsilon_{p} / 2=0.2 \%$, the softening obtained in the present study (123 $\mathrm{MPa}$ ) was much lower than that reported in [11] (165 MPa) for similar experimental conditions. Moreover the $\gamma^{\prime}$ precipitates of [11] had a mean diameter of $5 \mathrm{~nm}$, a distance between the precipitates of $18 \mathrm{~nm}$ and a volume fraction of $8.1 \%$ while $\gamma^{\prime}$ precipitates of our study had a mean diameter of $3.4 \mathrm{~nm}$. It is suggested that the cyclic softening is strongly linked to the $\gamma^{\prime}$ precipitates size and to the initial chemical composition of the alloy which was slightly different in [11].

\subsection{Deformed microstructure}

For each LCF test, related microstructures were studied to determine the plastic strain amplitude range leading to the formation of planar deformation structures. Typical bright and dark field TEM images are reported in Fig. 7. The strained microstructure

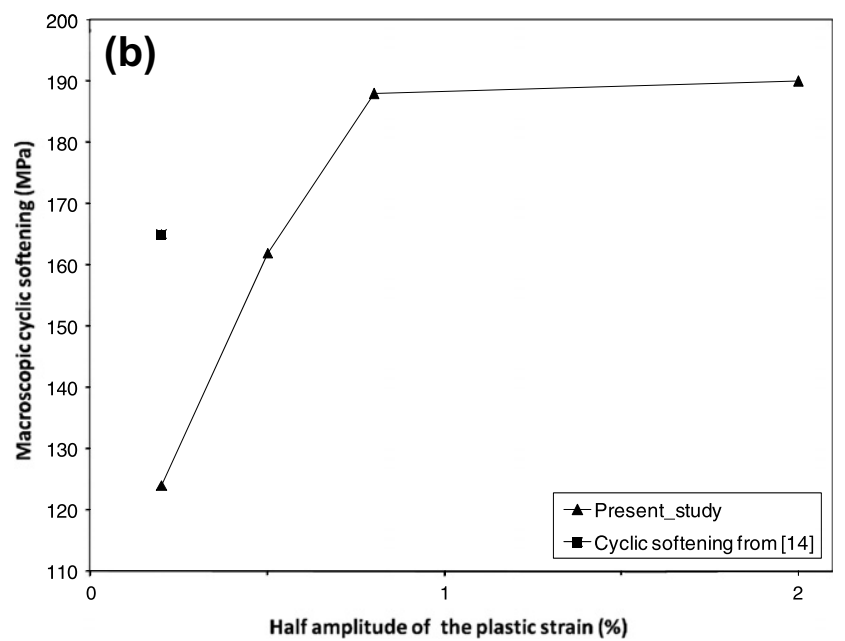

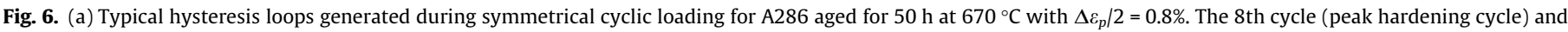
the 150 th cycle (cyclic softening) are displayed. (b) Macroscopic cyclic softening versus plastic strain amplitude. 
(c)

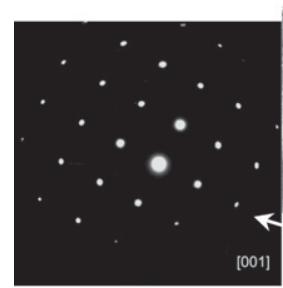

Selected area diffraction pattern with smaller aperture localised on the defect: no $\gamma^{\prime}$ spots

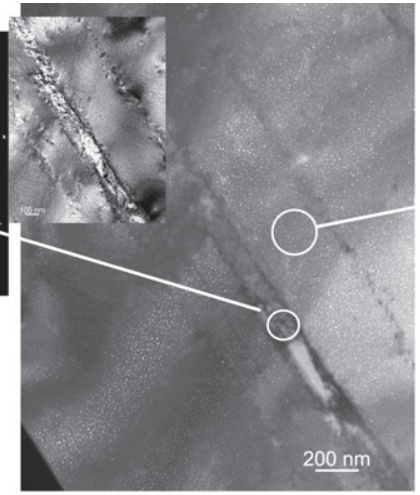

Free precipitates localization band (d)

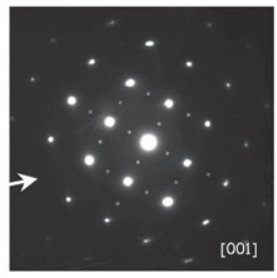

Selected area diffraction pattern with smaller aperture localised outside the defect: $\gamma$ ' spots occurs

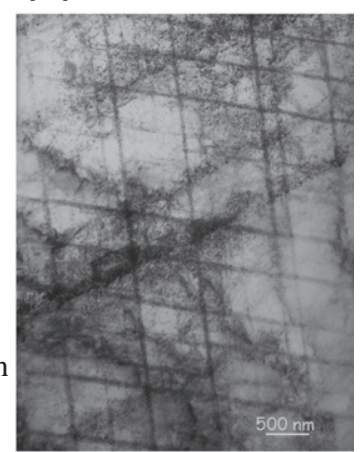

No localization, grains highly deformed

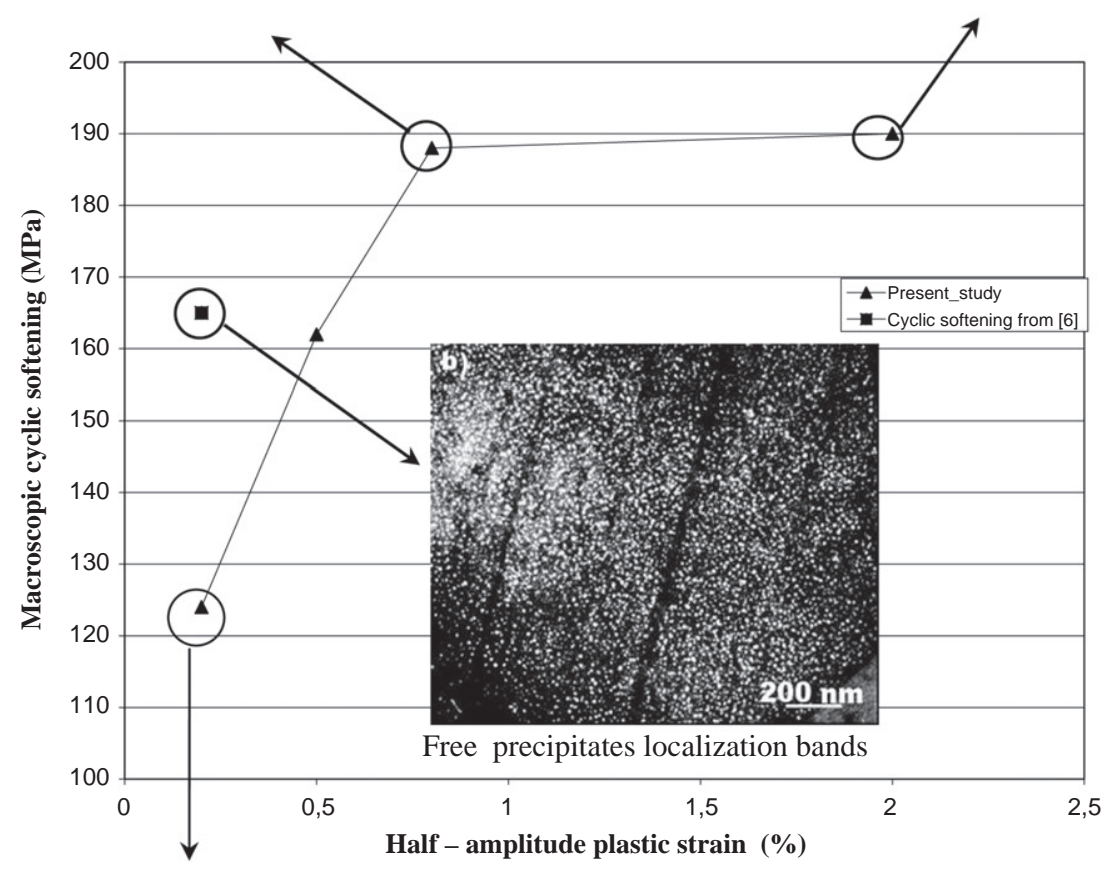

(a)

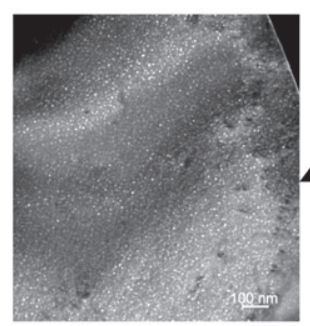

$\gamma^{\prime}$ phase precipitation between deformation bands



Deformation bands activated along two slip systems, no localization bands

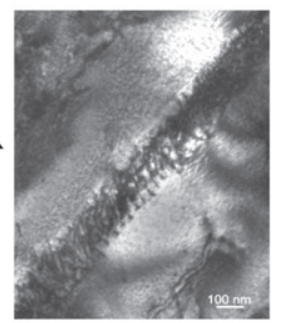

Dislocations pile - up making deformation band

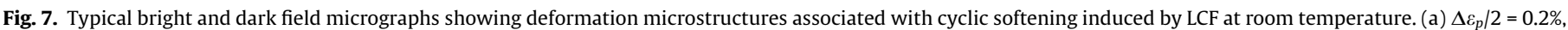
(b) $\Delta \varepsilon_{p} / 2=0.2 \%$, from [11], (c) $\Delta \varepsilon_{p} / 2=0.8 \%$ and (d) $\Delta \varepsilon_{p} / 2=2 \%$.

associated to cyclic softening induced by LCF at plastic strain amplitudes from $0.2 \%$ to $2 \%$ is shown in this figure.

Fig. 7a shows images corresponding to the specimen submitted to 1000 cycles at $0.2 \%$ of plastic strain. Stacks of dislocations lying along $\langle 111\rangle$ slip planes are observed, and between these plans, $\gamma^{\prime}$ phase coherent with the $\gamma$ matrix was present. During cyclic softening, two slip systems are activated and the resulting bands are intense for both systems. At saturation of cyclic softening (1000 cycles), all slip systems are persistent but no $\gamma^{\prime}$-free bands are observed, even if deformation is localized in intense bands. 


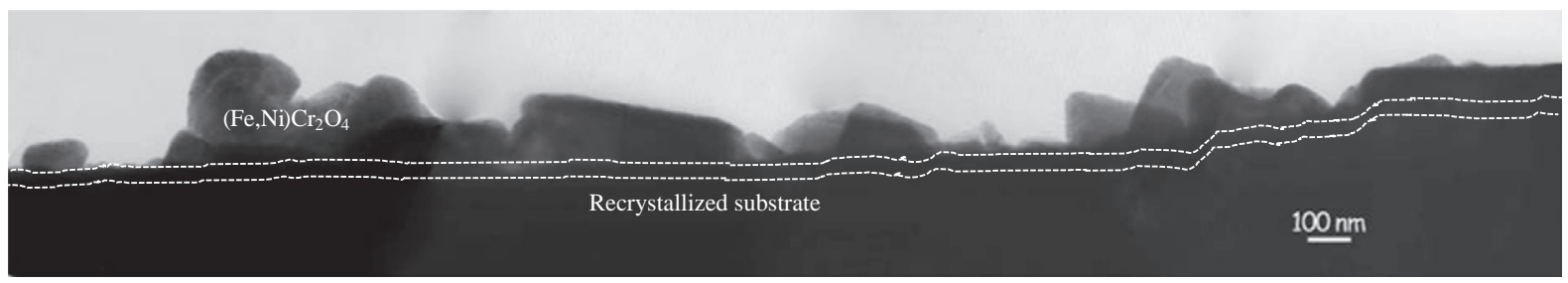

Fig. 8. Bright field image of the oxide layer cross section after exposure of non-precycled, aged A286 alloy to simulated reactor primary water ( $340{ }^{\circ} \mathrm{C}$, $500 \mathrm{~h}$ ).

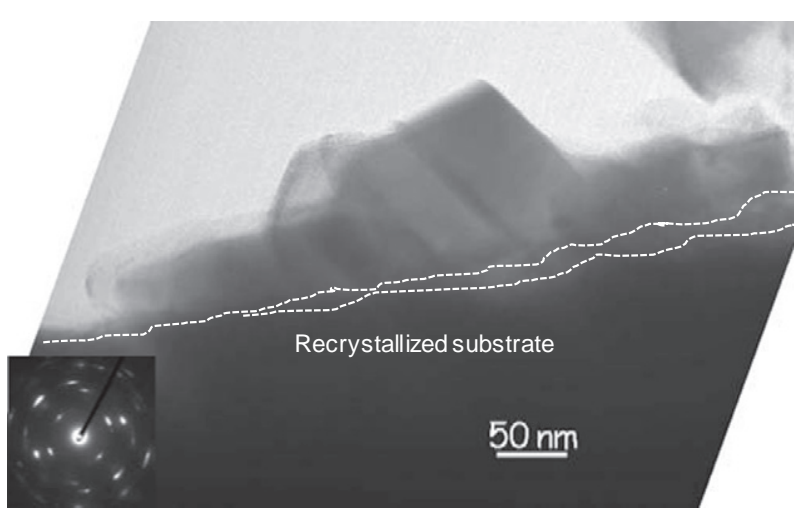

Fig. 9. Bright field image of the oxide layer after exposure to simulated reactor primary water $\left(340{ }^{\circ} \mathrm{C}, 500 \mathrm{~h}\right)$ of precycled $(0.8 \%, 116$ cycles $)$ aged $\mathrm{A} 286$ alloy.

For the same cycling conditions, the microstructural characteristics in our study were different from those reported in [11] where it was observed that during cyclic softening, two slip systems were formed, one corresponding to intense deformation bands, and the other to low-intensity bands. At saturation of cyclic softening, all deformation bands were present and only one slip system was persistent (that corresponding to low-intensity bands). However, clear localization bands are present, as seen in the dark field TEM micrograph (Fig. 7b) [11]. The specimen was submitted to 120 LCF cycles for $0.2 \%$ half-plastic strain amplitude.

This difference in microstructure for the two grades is supported by macroscopic softening at $165 \mathrm{MPa}$ in Fournier's study [11] while softening occurred at $123 \mathrm{MPa}$ in our study for the same half-plastic strain amplitude. These two parameters (deformation microstructure and cyclic softening) are actually linked, but indirectly. The microscopic softening difference is due to the strength of precipitates to the motion of dislocation in slip planes during the shearing of precipitates in softening phase. The size of $\gamma^{\prime}$ precipitates [11] is higher than that of our study and it results in higher microscopic cyclic softening value.

In terms of localization of plastic deformation in strong bands, the parameter of comparison between the two grades is the inter-slip bands distance, when the deformation is confined within the band. The space width between the bands is higher in the study of Fournier $(\sim 220 \mathrm{~nm})$ compared to our study $(\sim 100 \mathrm{~nm})$. The deformation is more localized in the grade used in [11] than in our study and this finding is significant for SCC tests.

The comparison between the two grades suggested that behaviour of the alloy under cyclic loading depends on the strength of the precipitates to the motion of dislocations in slip planes during cycling and the ability of material to redistribute the accumulated plastic strain in the matrix.

Fig. 7c displays the dark field image of a specimen that underwent 116 cycles at $0.8 \%$ using the superlattice reflexion $(010) \gamma^{\prime}$ of the zone axis [001]. A precipitate-free band, close to $100 \mathrm{~nm}$ wide, surrounded by a $\gamma$ matrix epitaxial with the $\gamma^{\prime}$ phase is clearly shown in this image. It is then concluded that the sample deformed for 116 cycles at $0.8 \%$ leads to strain localization in precipitate-free bands. Since these bands are free of obstacles, the dislocations move in slip planes, deformation being easily accommodated in these bands and becoming highly localized during cyclic loading.

For a plastic-strain half amplitude of $2 \%$, the result is quite different from that expected. A typical bright-field TEM image from a specimen subjected to 173 cycles at $2 \%$ is reported in Fig. $7 d$. Many deformation bands along two slip systems are observed. Unlike previous observations, dense dislocation tangles are noted throughout the matrix between deformation bands. For these cyclic conditions, deformation appears to be widespread in some grains, suggesting that cycling with a high plastic amplitude tends to homogenize deformation, due to a higher number of activated slip planes.

To conclude, regarding the above microstructural features, there is a plastic strain range corresponding to heterogenic localized deformation. This suggests that beyond a certain level of plastic strain, deformation becomes homogenized. This phenomenon also occurred in 304L stainless steel as reported in [15]. The authors report that when plastic stain increases, the number of activated slip planes also increases, and when critical strain is achieved, slip bands intercept each other to result in dislocation cells. High levels of strain are thus not propitious for planar deformations.

\subsection{Static oxidation and localized deformation}

\subsubsection{Pre-deformation effects on static oxidation of A286 alloy}

A comparative study was performed between the oxides that grew during exposure of non-precycled and precycled alloy to simulated reactor primary water. Two cycling conditions were studied: 116 cycles at $0.8 \%$ (where $\gamma^{\prime}$-free bands developed) and 350 cycles at $0.5 \%$. The aim was to identify any modifications of surface reactivity induced by the presence of $\gamma^{\prime}$ - free deformation bands.

A cross section showing the surface layer of the non-precycled alloy after $500 \mathrm{~h}$ at $340{ }^{\circ} \mathrm{C}$ is reported in Fig. 8 .

The surface layer is inhomogeneous and composed of two distinct strata: the external oxide layer and the internal or interfacial oxide layer.

The external oxide layer is composed of facetted crystallites, not exceeding lengths of $300 \mathrm{~nm}$. These crystallites are enriched with Fe (up to 61 at.\%) and also contain $\mathrm{Cr}$ (up to 18 at.\%) and $\mathrm{Ni}$ (up to 21 at.\%). According to the chemical composition determined by EDX analyses, these crystallites are close to spinel ( $\mathrm{Fe}, \mathrm{Ni}) \mathrm{Cr}_{2} \mathrm{O}_{4}$.

They are dispersed on top of the internal oxide layer, which is compact and enriched in chromium. The thickness of this layer, also named interfacial layer, varies from 20 to $30 \mathrm{~nm}$. The duplex nature of the oxide layer morphology for an austenitic stainless steel exposed to reactor primary water has been reported by many authors [16-20].

In the vicinity of the interfacial layer, the substrate is disordered to a depth of $190 \mathrm{~nm}$. This disruption leads to the recrystallization of the initial austenitic grains, resulting in finer, generally elongated, grains. 

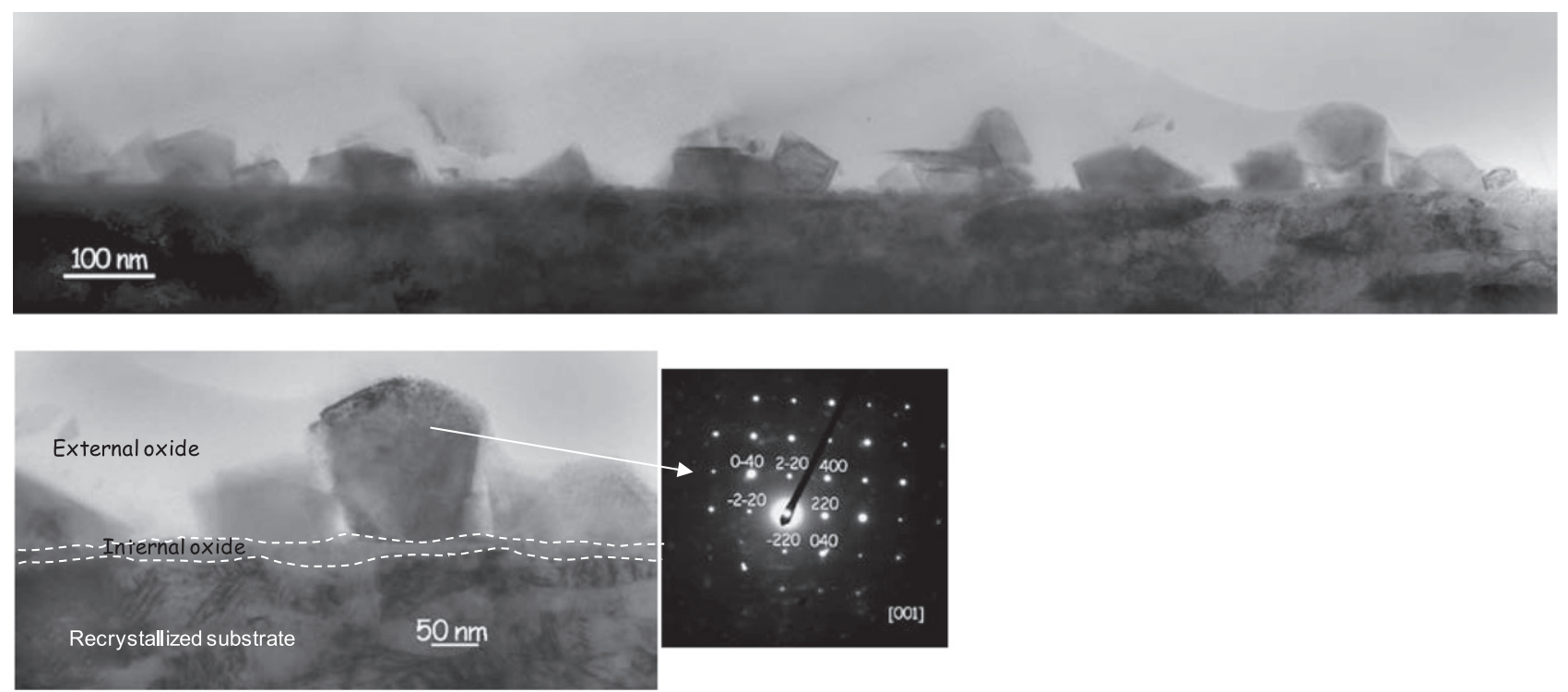

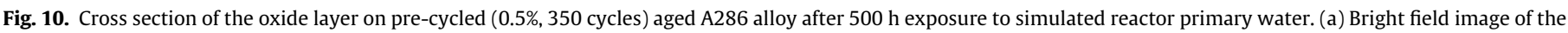
oxide layer and (b) crystallite of magnetite associated with its diffraction pattern (zone axis [001]).

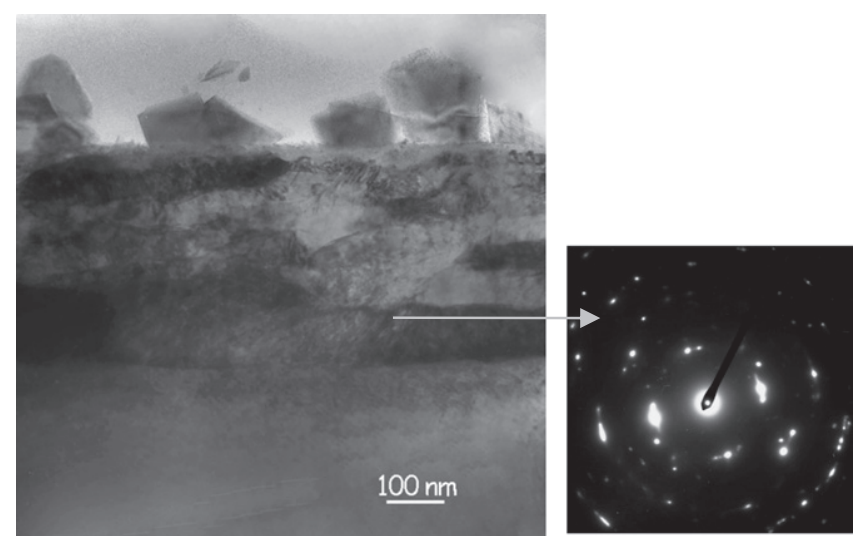

Fig. 11. Bright field image showing elongated nanograins in the substrate and a specific diffraction pattern in the recrystallized area.

The cross section of the surface layer created on the pre-cycled sample ( $0.8 \%$ for 116 cycles) exposed to simulated reactor primary water is displayed in Fig. 9.

This image (Fig. 9) displays the same oxide morphology as that of the non-precycled samples. The surface oxide layer is composed of: an external oxide, inhomogeneous, porous and made up of crystallites of up to $200 \mathrm{~nm}$ in length, and containing 70 at.\% iron but also nickel (up to 25 at.\%) and a little chromium (up to 5\%). The chemical composition determined by EDX analysis suggests that the external layer is composed of spinel $(\mathrm{Fe}, \mathrm{Ni}) \mathrm{Cr}_{2} \mathrm{O}_{4}$. Below this there is an internal oxide layer rich in chromium (thickness $10 \mathrm{~nm}$ ) and recrystallized substrate to a depth of $500 \mathrm{~nm}$.

A cross section showing the oxide layer of the precycled alloy ( $0.5 \%$ for 350 cycles) is reported in Fig. 10 .

The external oxide is composed of crystallites of $(\mathrm{Fe}, \mathrm{Ni}) \mathrm{Cr}_{2} \mathrm{O}_{4}$, as determined by the diffraction pattern along the zone axis [001] and EDX analysis. Moreover, EDX analysis revealed that the chromium concentration increased in the oxide up to the oxide/substrate interface (50-60 at.\%). This internal oxide layer is compact and can reach a thickness of $20 \mathrm{~nm}$ (Fig. 10b). It is composed of small crystallites revealed by HRTEM (high-resolution TEM).
Finally, under the internal layer, the substrate is recrystallized and composed of elongated nanograins to a depth of $500 \mathrm{~nm}$ (Fig. 11). This is shown by the diffraction pattern of this area, characteristic of a disordered zone, with cold working dislocations. However, no evidence of $\gamma^{\prime}$-free bands at the substrate/oxide layer interface was observed.

Note that EDX chemical analysis showed that the area with recrystallized grains in the bulk, down to $100 \mathrm{~nm}$, was enriched in nickel reaching 32 at.\% (and depleted in chromium) in the two pre cycled samples. The depletion of chromium from the bulk may be an important feature regarding intergranular oxide penetration. This will be discussed in the following part.

In conclusion, the morphology of the oxides that form on the alloy in the two microstructural states (pre-cycled and nonpre-cycled) is quite similar, except for the size of the duplex oxide layers. The pre-deformation (including microstructural modifications) appears to weakly affect the surface reactivity of the alloy during oxidation in the PWR environment. Moreover, the presence of $\gamma^{\prime}$ free deformation bands (sample precycled $0.8 \%, 116$ cycles) did not lead to a more reactive surface (i.e. did not change the morphology or thickness of oxide layer) compared to samples for which $\gamma^{\prime}$ free bands are not displayed (sample precycled $0.5 \%$, 350 cycles). Finally, no interactions were observed between the $\gamma^{\prime}$ free bands and the oxide layer ruling out a possible hypothesis of oxide growth along these localized deformation bands.

For pre-cycled samples, however, the recrystallized area was partially (in the direct vicinity of the oxide layer) chromium depleted (10 at.\%). This recrystallized area was found to occur to a depth of $100 \mathrm{~nm}$ in the bulk. Could it be the consequence of the presence of intergranular oxide penetration in the subsurface?

To obtain insights into this question, R-SIMS analyses are carried out to investigate the presence of intergranular oxides in the pre-cycled sample.

\subsubsection{Study of intergranular oxide penetration}

The elements located in the matrix underlying the oxide layer were characterized by SIMS analysis. Since the beam erodes the sample from the base metal to the oxide, reverse-SIMS analyses were performed for an A286 sample (cycled at $0.8 \%$ for 116 cycles) exposed to simulated reactor primary water. The technique gives information about the diffusion profiles of different elements of 


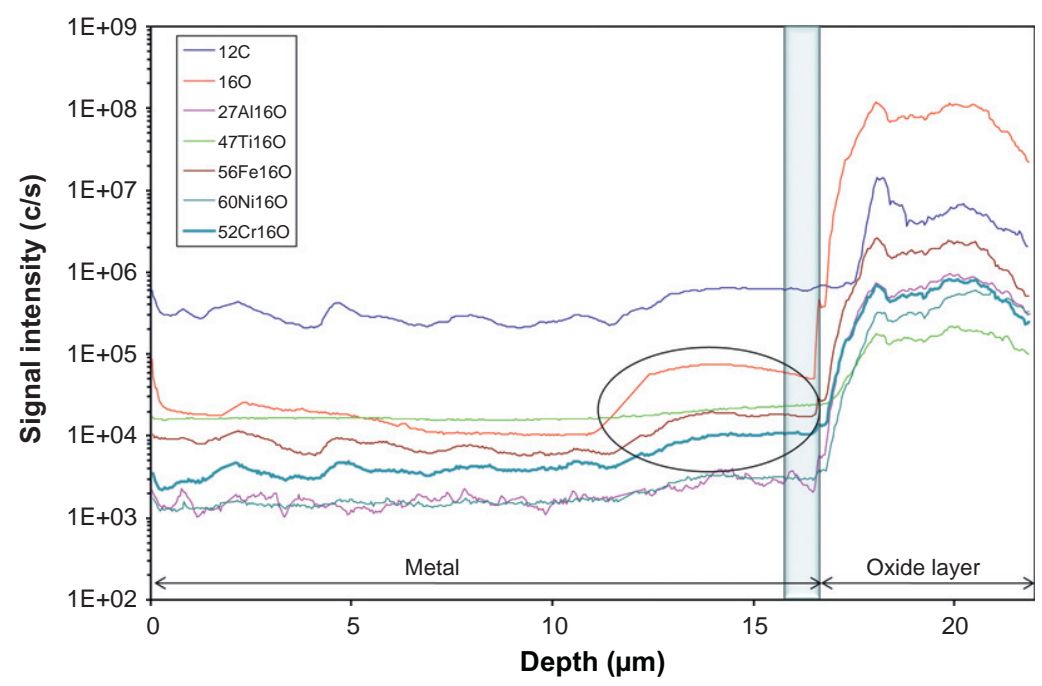

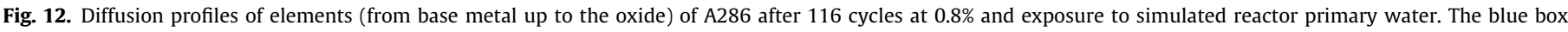

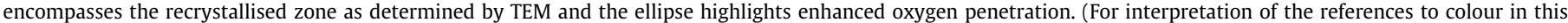
figure legend, the reader is referred to the web version of this article.)

interest, and also about oxides which may be located in the sublayer. At a precise depth from the analyzed surface of the sample, each element may be mapped if necessary. In addition to the oxygen diffusion profile $\left({ }^{16} \mathrm{O}\right)$, the profiles of the following features were displayed:

$-{ }^{12} \mathrm{C}$ : the tracing of carbon element gave indications of grain boundary location in the oxide subsurface or in the bulk. In fact the ageing heat treatment leads to systematic precipitation of different carbide types at grain boundaries.

$-{ }^{27} \mathrm{Al}^{16} \mathrm{O}$ : Aluminum is thermodynamically reactive with oxygen in high temperature water and is preferentially oxidized; aluminum oxide is then systematically detected.

$-{ }^{56} \mathrm{Fe}^{16} \mathrm{O}$ (iron oxide), ${ }^{60} \mathrm{Ni}^{16} \mathrm{O}$ (nickel oxide), ${ }^{52} \mathrm{Cr}^{16} \mathrm{O}$ (chromium oxide) and ${ }^{47} \mathrm{Ti}^{16} \mathrm{O}$ (titanium oxide) for major elements constituting the alloy.

The elemental intensity signal versus depth, from the base metal to the oxide layer for ${ }^{16} \mathrm{O}$ and ${ }^{12} \mathrm{C}$ and for the metal oxides $\left({ }^{16} \mathrm{OTi},{ }^{16} \mathrm{OCr},{ }^{16} \mathrm{OAl},{ }^{16} \mathrm{OFe}\right.$ and $\left.{ }^{16} \mathrm{ONi}\right)$ is reported in Fig. 12.

Along the base metal, the intensity of the aluminum oxide signal (as well as of carbon, titanium oxide and chromium oxide) is quite regular and stable, but showed a sharp increase in the outer oxide layer. For the oxygen signal, the intensity was also relatively constant in the first $11 \mu \mathrm{m}$ in the base metal and sharply increased when the beam reached the oxide layer. However, at $5 \mu \mathrm{m}$ from the oxide layer the oxygen signal presents a singularity in the base metal. This singularity is similar to that observed for the chromium oxide, the nickel oxide and the iron oxide signals. It suggests the presence of dissolved oxygen and/or intergranular penetrations (e.g. chromium, nickel and iron oxide-spinel type $\left.(\mathrm{Fe}, \mathrm{Ni}) \mathrm{Cr}_{2} \mathrm{O}_{4}\right)$ connected to the oxide layer, at a depth of $15 \mu \mathrm{m}$ in the base metal. In order to confirm the presence of oxide penetration, the levels of different components $\left({ }^{12} \mathrm{C},{ }^{16} \mathrm{O},{ }^{16} \mathrm{O}{ }^{52} \mathrm{Cr},{ }^{16} \mathrm{O}{ }^{56} \mathrm{Fe}\right)$ were mapped at two depths: $5 \mu \mathrm{m}$ and $15 \mu \mathrm{m}$ where the oxygen signal intensity was disrupted and are displayed in Fig. 13. The nickel component map $\left({ }^{16} \mathrm{O}^{60} \mathrm{Ni}\right.$ - not shown here) is similar to ${ }^{16} \mathrm{O}^{52} \mathrm{Cr},{ }^{16} \mathrm{O}^{56} \mathrm{Fe}$ maps.

Mapping the levels of ${ }^{12} \mathrm{C}$ element at 5 and $15 \mu \mathrm{m}$ depth showed that the signal was intensified at precise areas surrounded by dark. The microstructural characterization of the aged alloy (Fig. 3) showed that $\gamma^{\prime}\left(\mathrm{Ni}_{3} \mathrm{Ti}\right)$ precipitates in epitaxis with austenitic $\gamma$ matrix, and also that secondary precipitation such as that of titanium and molybdenum carbides, is systematically displayed (Fig. 3). It had been shown that the larger carbides (up to $2.5 \mu \mathrm{m}$ ) are located at the grain boundaries where it forms dense strings. Intragranular precipitates are very rare, scattered in the matrix and their size does not exceed $600 \mathrm{~nm}$. The intergranular precipitates will be more reactive to chemical analysis than those located in the matrix (intragranular ones). Indeed, the intense areas displayed on the carbon maps (Fig. 13) represent the different carbides located at grain boundaries and the dark areas the matrix. Thus, mapping ${ }^{12} \mathrm{C}$ element permitted us to trace the grain boundaries in the bulk $(5 \mu \mathrm{m})$ or in the subsurface, in the vicinity of the oxide layer $(15 \mu \mathrm{m})$.

Fig. 13 also displays the maps of ${ }^{16} \mathrm{O}$ element, and as expected from the diffusion profile (Fig. 12), the intensity signal at $15 \mu \mathrm{m}$ is higher than that at $5 \mu \mathrm{m}$. However, at $15 \mu \mathrm{m}$, it can be noted that the oxygen signal is intensified in areas identified as grain boundaries (represented by dotted lines); this suggests that grain boundaries are preferentially oxidized in the subsurface. The map of chromium, iron and nickel oxide (not shown here) at $15 \mu \mathrm{m}$ supports this idea, confirming the presence of chromium, nickel and iron oxide or of an oxide enriched with chromium, nickel and iron at grain boundaries in the subsurface under the oxide layer, as in the bulk, these oxide penetrations do not exist. Therefore, the evidence strongly suggests intergranular penetration (spinel type (Fe, $\mathrm{Ni}) \mathrm{Cr}_{2} \mathrm{O}_{4}$ ) when the pre-cycled alloy is exposed to simulated reactor primary water. Similar evidence has been validated by Bruemmer [21], whose study reported intergranular penetrations for a 316L core exposed to a BWR and a PWR environment.

Note that the recrystallized nanograins (blue areas in Fig. 12) are included in this $5 \mu \mathrm{m}$ area of intergranular penetrations that may explain the depletion of chromium in the bulk highlighted in the last section, the amount of chromium available in the bulk being used in grain boundaries for intergranular precipitation. Moreover, 3D tomography of ${ }^{16} \mathrm{O}$ element (not shown here) shows that the oxygen is segregated in subsurface along the grain boundaries (shown in Fig. 13) and not along the localized deformation bands (width $\sim 100 \mathrm{~nm}$ ).

In conclusion, pre-cycling the aged A286 alloy did not modify the surface reactivity in terms of morphology, composition or thickness of the oxide layers. In addition, no interaction between the $\gamma^{\prime}$ free band and the oxide layer was observed in this study: localization bands were not preferential channels of oxide 

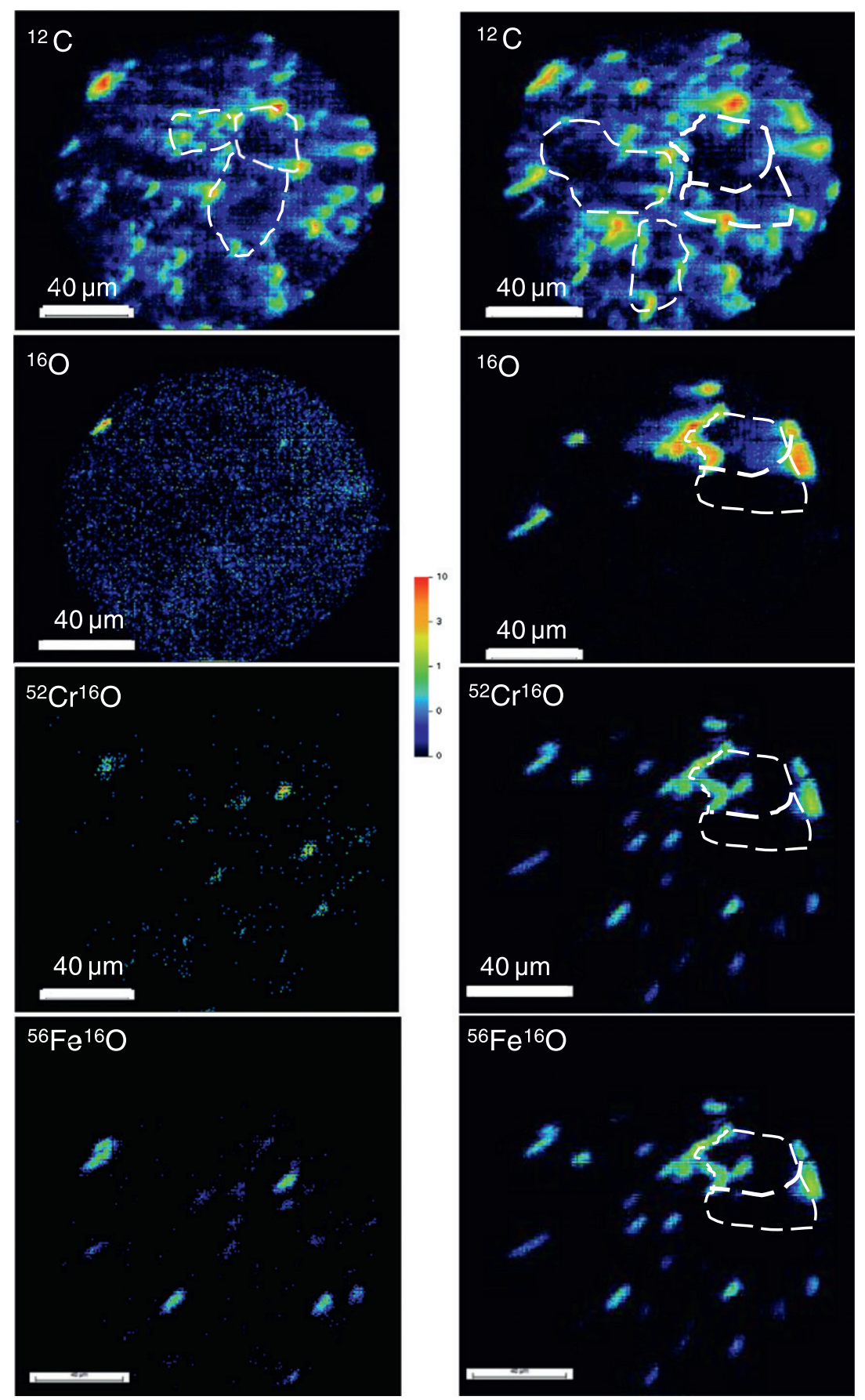

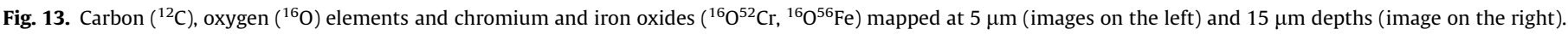
Note that the dotted lines indicate the outlines of intergranular penetrations.

penetration in the base metal. This conclusion is in opposition to studies $[16,20,22,23]$, reporting that the deformation bands present in 304L stainless steel exposed to PWR water may enhance the oxidation rate. For example, Lozano-Perez et al. [23] indicate that prior cold work may facilitate oxidation in deformation bands by providing a density of dislocations acting as fast diffusion paths for oxygen and iron. He also explains that applied stress may enhance the effects of cold work and accelerate oxidation rates. It can also be pointed out that the rolling technique used in these studies results in a higher degree of cold work, characterized by deformation bands (defect-free deformation bands in our study). However, in the present study which concerns A286 grade stainless steel pre-deformed by means of LCF, interactions between the deformation bands and oxide penetration are not shown. Actually, the intergranular penetrations take place in the subsurface. This information is interesting, because intergranular penetrations may weaken grain boundaries and, when a stress is applied (stress corrosion cracking), critical interactions may be located at the intersections between grain boundaries and localized deformation bands.

\subsubsection{Stress corrosion cracking and localized deformation}

Results of slow strain-rate tests (SSRT) will not be discussed in this paper. However, the approach is displayed here. Specimens 
with and without localized deformation, were tested in simulated PWR primary water under constant strain rate $\left(8.8 \times 10^{-8} / \mathrm{s}\right)$. In order to evaluate a quantitative effect of localized deformation, specimens with the different pre-deformation strain levels detailed in this study were also tested in SCC.

A similar approach was used in [11]: specimens with and without deformation localization subjected to the same yield strength were exposed to PWR primary water at 320 and $360^{\circ} \mathrm{C}$. The yield strength was identified as a determining parameter in SCC susceptibility of A286 [11] so attention was paid to reach the same flow stress in order to ensure that plastic localization was the only parameter affecting SCC. The study indicated that specimens precycled up to softening exhibited higher IGSCC susceptibility with percentage IG cracking up to $16 \%$ for specimens pre-cycled for 200 cycles at $0.2 \%$. Specimens with a few fatigue cycles that did not contain precipitate-free localized deformation bands exhibited little or no SCC susceptibility while specimens with several tens of fatigue cycles contained precipitate-free localized deformation bands and exhibited significant SCC susceptibility.

The SSRT tests are currently being carried out and are expected to bring complementary information. The link between the local microstructure and fracture appearance will then be investigated as function of plastic deformation pre straining level.

\section{Conclusions}

This work investigated the detrimental effects of deformation localization on SCC susceptibility of austenitic steels in PWR primary water. A286 precipitation-strengthened austenitic stainless steel specimens were mechanically cycled by LCF tests $\left(\Delta \varepsilon_{p} / 2=0.2 \%, 0.5 \%, 0.8 \%\right.$ and $2 \%$ plastic strain at RT) to simulate localization features. The microstructure of the aged $\left(670^{\circ} \mathrm{C}\right.$, $50 \mathrm{~h})$ A286 shows an austenitic matrix, coherent with the $\gamma^{\prime}\left(\mathrm{Ni}_{3} \mathrm{Ti}\right)$ phase and the presence of carbides (titanium and chromium carbides) and small phosphide precipitates towards the grains. Intergranular precipitates were systematically observed.

The influence of pre-cycling on surface reactivity and on the interaction between oxidation and localized deformation bands was studied. The main results are:

(1) The behaviour of precipitation-strengthened A286 during the LCF cycling presented three phases: a hardening phase followed by softening and finally saturation of the softening.

(2) Plastic deformation localization was observed to mainly occur along two intense slip planes. Localized deformation bands are displayed.

(3) For similar cycling conditions ( $0.2 \%$ strain imposed for 1000 cycles) softening of the grade of stainless steel studied here (at $123 \mathrm{MPa}$ ) was lower than that reported by Fournier et al. (165 MPa) [11]. The lower macroscopic softening in the precipitation-hardened A286 of this study is due to the fact that $\gamma^{\prime}$ size is higher in the study of Fournier. Plastic deformation localization appears to depend on interband space width of slip bands developed during the cycling of the steel.

(4) The occurrence of plastic deformation localization in bands is not a critical criterion for surface reactivity of the alloy in terms of morphology, composition or thickness of the oxide layers. Moreover TEM and SIMS analysis showed that oxide growth was not enhanced along the localization bands without the imposition of strain during oxidation.

(5) Intergranular oxidation was observed to take place in the subsurface under the oxide layer during exposure to PWR primary water.

Slow strain rate tests are expected to give more quantitative indications about IGSCC sensitivity of the stainless steel grades used and its relations to deformation mode.

\section{Acknowledgments}

We gratefully acknowledge L. Vincent and P. Wident from DMN/SRMA (CEA Saclay) and T. Morgeneyer (Centre des Matériaux, Mines Paristech) for conducting the mechanical tests, M.H. Mathon from Leon Brillouin laboratory (CEA Saclay) for conducting DNPA measurements, C. Guerre from DPC/SCCME (CEA Saclay) for providing facilities used for oxidation tests, Anne Maquignon and E. Herms from DPC/SCCME (CEA Saclay) for their assistance in preparing and conducting the SCC tests, and C. Armand from INSA (Toulouse) for conducting the SIMS experiments.

\section{References}

[1] G.S. Was, J.T. Busby, Philos. Mag. 85 (4-7) (2005) 443-465.

[2] G.S. Was, S.M. Bruemmer, J. Nucl. Mater. 216 (1994) 326-347.

[3] S.M. Bruemmer, E.P. Simonen, P.M. Scott, P.L. Andersen, J. Nucl. Mater. 274 (1999) 299-314.

[4] H.M. Chung, W.E. Ruther, J.E. Sanecki, A. Hins, N.J. Zaluzec, T.F. Kassner, in: Proceedings of the JIM '95 Fall Annual Meeting (117th) on Lattice Defects and Radiation Induced Phenomena, J. Nucl. Mater, vol. 239, 1996, pp. 61-79.

[5] J.M. Cookson, R.D. Carter Jr, D.L. Damcott, M. Atzman, G.S. Was, J. Nucl. Mater 202 (1993) 104-121.

[6] K. Fukuya, M. Nakano, K. Fujii, T. Torimaru, J. Nucl. Sci. Technol. 41 (2004) 594600.

[7] T. Onchi, K. Doh, N. Soneda, J.R. Cowan, R.J. Scowen, M.L. Castano, J. Nucl. Mater. 320 (2003) 194-208.

[8] T. Onchi, K. Doh, N. Soneda, M. Navas, M.L. Castano, J. Nucl. Mater. 340 (2005) 219-236.

[9] Z. Jiao, J.T. Busby, G.S. Was, in: TMS 2007:Wechsler Symposium, Proceedings of the Symposium on Radiation Effects, Deformation and Phase Transformations in Metals and Ceramics, organized in honor of Prof. Monroe S. Wechsler, vol. 361(2-3), 2007, pp. 218-227.

[10] Z. Jiao, G. Was, J. Nucl. Mater. 407 (2010) 34-43.

[11] L. Fournier, M. Savoie, D. Delafosse, J. Nucl. Mater. 366 (2007) 187-197.

[12] A.J.E. Foreman, J.V. Sharp, Philos. Mag. 19 (1969) 931-937.

[13] A.S. Argon, E. Orowan, Physics of Strength and Plasticity, M.I.T. press ed., 1969

[14] M. Savoie, Influence de la localisation de la déformation sur la corrosion sous contrainte de l'acier inoxydable austénitique A-286 en milieu primaire des REP, PhD thesis, Ecole Nationale Supérieure des mines de Saint Etienne, 2007.

[15] D. Ye, Y. Xu, L. Xia, H. Cha, Mater. Sci. Eng. A 527 (2010) 4092-4102.

[16] T. Terachi, K. Fujii, K. Arioka, J. Nucl. Sci. Technol. 42 (2005) 225-232.

[17] J. Robertson, Cor. Sci. 29 (1989) 1275-1291.

[18] T. Couvant, P. Moulart, L. Legras, P. Bordes, J. Capelle, Y. Rouillon, T. Balon, in: Proc. 13th Int. Conf. Environ. Degradation of Materials in Nuclear Power Systems-Water Reactors. CNS, CDROM, 2007.

[19] B. Stellwag, Cor. Sci. 40 (1998) 337-370.

[20] S. Lozano-Perez, D.W. Saxey, T. Yamada, T. Terachi, Scripta Mater. 62 (2010) $855-858$.

[21] S. Bruemmer,Surface damage and Environment-Assisted Cracking Precursors in LWR Components. in: SCC Initiation Workshop, Beaune, Bourgogne, France, 2008.

[22] S. Lozano-Perez, T. Yamada, T. Terachi, M. Schroder, C.A. English, G.D.W. Smith, C.R.M. Grovenor, B.L. Eyre, Acta Mater. 57 (2009) 5361-5381.

[23] S. Lozano-Perez, K. Kruska, I. Iyengar, T. Terachi, T. Yamada, Cor. Sci. 56 (2012) $78-85$. 